\title{
Effect of magnesium supplementation on emergence delirium and postoperative pain in children undergoing strabismus surgery: a prospective randomised controlled study
}

Ji-Hyun Lee, Seungeun Choi, Minkyoo Lee, Young-Eun Jang, Eun-Hee Kim, Jin-Tae Kim and Hee-Soo Kim*i]

\begin{abstract}
Background: The benefits of intraoperative magnesium supplementation have been reported. In this prospective, randomized study, the effects of magnesium supplementation during general anaesthesia on emergence delirium and postoperative pain in children were evaluated.

Methods: A total of 66 children aged 2 to 5 years who underwent strabismus surgery were assigned to the magnesium or to the control group. Preoperative anxiety was assessed using the modified Yale Preoperative Anxiety Scale. After anaesthesia induction, the magnesium group received an initial loading dose of $30 \mathrm{mg} / \mathrm{kg}$ magnesium sulphate over $10 \mathrm{~min}$ and, then, continuous infusion of $10 \mathrm{mg} / \mathrm{kg}$ per $\mathrm{h}$ until $10 \mathrm{~min}$ before the end of the surgery. The control group received an equal volume of normal saline via the same regimen. The Paediatric Anaesthesia Emergence Delirium (PAED) score, pain score, and respiratory events were assessed at the postanaesthetic care unit.
\end{abstract}

Results: Data obtained from 65 children were analyzed. The PAED and pain scores of the two groups did not differ significantly. There were 26 of $33(78.8 \%)$ and 27 of 32 (84.4\%) children with emergence delirium in the control and the magnesium groups, respectively (odds ratio $0.69,95 \% \mathrm{Cl} 0.19-2.44 ; p=0.561$ ). The preoperative anxiety score was not significantly correlated with the PAED score. The incidence of respiratory events during the emergence period did not differ significantly between the two groups.

Conclusions: Magnesium supplementation during anaesthesia had no significant effects on the incidence of emergence delirium or postoperative pain in children undergoing strabismus surgery.

Trial registration: ClinicalTrials.gov (NCT03132701). Prospectively registered May 8, 2017.

Keywords: Emergence delirium, Magnesium, Ophthalmologic surgical procedure, Paediatrics, Pain

\footnotetext{
* Correspondence: dami0605@snu.ac.kr

Department of Anaesthesiology and Pain Medicine, Seoul National University Hospital, Seoul National University College of Medicine, \# 101 Daehakno,

Jongnogu, Seoul 03080, Republic of Korea
}

(c) The Author(s). 2020 Open Access This article is licensed under a Creative Commons Attribution 4.0 International License, which permits use, sharing, adaptation, distribution and reproduction in any medium or format, as long as you give appropriate credit to the original author(s) and the source, provide a link to the Creative Commons licence, and indicate if changes were made. The images or other third party material in this article are included in the article's Creative Commons licence, unless indicated otherwise in a credit line to the material. If material is not included in the article's Creative Commons licence and your intended use is not permitted by statutory regulation or exceeds the permitted use, you will need to obtain permission directly from the copyright holder. To view a copy of this licence, visit http://creativecommons.org/licenses/by/4.0/ The Creative Commons Public Domain Dedication waiver (http://creativecommons.org/publicdomain/zero/1.0/) applies to the data made available in this article, unless otherwise stated in a credit line to the data. 


\section{Background}

Emergence delirium after general anaesthesia is a common phenomenon, and rates $>80 \%$ have been reported in children [1]. It has been associated with fast-acting inhalation anaesthetics, such as sevoflurane or desflurane, male sex, ophthalmology and otolaryngology procedures, younger age, and preoperative anxiety, and its incidence has been shown to be reduced by intraoperative opioids, benzodiazepine, and alpha 2 adrenergic agonists [2].

Magnesium is the fourth most common cation in the human body and known to be a modulator of transmembrane ion transport and energy metabolism [3]. Magnesium sulphate is an N-methyl-D-aspartate receptor antagonist that is used to treat hypomagnesemia, preeclampsia and polymorphic ventricular arrhythmia, and also used as an anti-convulsive agent. Additionally, the use of magnesium during the perioperative period has been associated with increased sedation, analgesia, reduced administration of neuromuscular blockade agents, and the prevention of ischemic-reperfusion injury $[4,5]$. In children, intraoperative infusion of magnesium may reduce emergence delirium after adenotonsillectomy [6] and hernia repair [7]. However, Apan et al. [8] reported that magnesium supplementation had no influence on the incidence of emergence delirium in paediatric patients.

Perioperative hypomagnesemia is common because some intravenous fluid solutions administered during fasting, including Hartman solution and normal saline, do not contain magnesium [9]. Therefore, magnesium supplementation during anaesthesia can reduce the required amounts of sedatives, analgesics, or neuromuscular blocking agents, and contribute to improved postoperative outcomes [10]. We hypothesised that magnesium supplementation in paediatric patients may also be associated with reductions in the amounts of anaesthetics and analgesics required, and reduced postoperative emergence delirium. Our aim was to evaluate the effects of magnesium supplementation during general anaesthesia on emergence delirium and postoperative pain in children undergoing strabismus surgery. Other post-anaesthesia recovery parameters, including nausea, vomiting, and respiratory complications, were also assessed.

\section{Methods}

\section{Study population}

This single-centre study was performed at the Seoul National University Children's Hospital, a tertiary children's hospital in South Korea. Sixty-six children aged 2-5 years (American Society of Anesthesiologists physical status I or II) who were scheduled for elective strabismus surgery under general anaesthesia were included. The exclusion criteria were as follows: history of hypersensitivity and malignant hyperthermia, currently taking an anti-epileptic drug, known myasthenia gravis, myasthenic syndrome, neuromuscular disease, arrhythmia, moderate cardiovascular, pulmonary, hepatobiliary, or renal disease, or overweight (body mass index $>85$ percentile). The study protocol was approved by the Institutional Review Board of the Seoul National University Hospital (approval number: H1703-110-840; date of approval: May 8, 2017) and was registered at https://clinicaltrials.gov (number: NCT03132701; principal investigator: Hee-Soo Kim; date of registration: April 9, 2017). The anaesthesiologists involved in the study obtained written informed consent from the parents or their guardians after explaining the study protocol to them.

\section{Group allocation}

This study was a randomised, controlled, parallel-designed trial. Following a simple randomisation procedure (computerised random number; https://www.randomizer.org), the children were allocated to the magnesium or the control group. An anaesthetic nurse who was not involved in the study prepared coded and sealed, opaque envelopes, and the allocation ratio was 1:1. Immediately before induction of anaesthesia, she prepared the study drug, either magnesium or normal saline, according to group allocation. The patients, attending anaesthesiologists, and two researchers (LJH and CSE) who assessed the preoperative anxiety and outcomes including delirium scale and pain score were blinded to group allocations.

\section{Anaesthesia and study protocol}

All strabismus surgeries were performed as day surgeries, and started before $11 \mathrm{am}$ according to the daysurgery policy of our centre. All patients had the following minimum fasting time; $8 \mathrm{~h}$ for heavy meal, $6 \mathrm{~h}$ for light meal and non-human milk, and $2 \mathrm{~h}$ for clear fluid. An intravenous line was established in all children before anaesthetic induction, and Ringer's lactate solution was administered before and during anaesthesia.

The extent of preoperative anxiety was assessed using the modified Yale Preoperative Anxiety Scale (m-YPAS) [11] when patients and their parents arrived at the reception area of the operating room. Anaesthesia induction was commenced with atropine $0.02 \mathrm{mg} / \mathrm{kg}$, propofol $2.5 \mathrm{mg} / \mathrm{kg}$ after electrocardiography monitoring, pulse oximetry, and non-invasive blood pressure determination. No other systemic or local analgesics, such as opioids or eye drops, were used during the induction period. Facemask ventilation was performed with sevoflurane and $100 \%$ oxygen and, then, a flexible laryngeal mask airway (Marshall flexible LAD ${ }^{\circ}$, Marshall Airway Products Ltd., Radstock, UK) was inserted. The intracuff pressure of the laryngeal mask airway was adjusted within 30-40 $\mathrm{cmH}_{2} \mathrm{O}$ using a cuff manometer (VBM Medizintechnik GmbH, Sulz am Neckar, Germany). Neuromuscular blocking agents were not used basically, but allowed as needed for the maintenance of 
anaesthesia. Mechanical ventilation was commenced using volume-controlled mode with tidal volume of 8 $\mathrm{ml} / \mathrm{kg}$ without positive end-expiratory pressure. During anaesthesia, sevoflurane concentration was controlled to maintain a bispectral index target between 40 and 60 .

At the beginning of anaesthesia induction, the children in the magnesium group received an initial intravenous loading dose of $30 \mathrm{mg} / \mathrm{kg}$ magnesium sulphate over $10 \mathrm{~min}(0.3 \mathrm{ml} / \mathrm{kg})$, then continuous infusion of $10 \mathrm{mg} / \mathrm{kg}(0.1 \mathrm{ml} / \mathrm{kg})$ per h until $10 \mathrm{~min}$ before the end of surgery. The control group received an equal volume of normal saline via the same infusion regimen. Preparations of ephedrine and atropine were readied for possible complications such as hypotension and bradycardia.

At the end of surgery, propacetamol $30 \mathrm{mg} / \mathrm{kg}$ was administered to all patients. After gentle pharyngeal suction, the laryngeal mask airway was removed and the patient was transferred to the postanaesthetic care unit (PACU). Complications during the emergence period, such as laryngospasm, bronchospasm, desaturation, breath holding, and coughing were recorded.
At the PACU, all patients' vital signs, including heart rate, noninvasive blood pressure, respiratory rate, and peripheral oxygen saturation, were continuously monitored and recorded every $5 \mathrm{~min}$. The Paediatric Anaesthesia Emergence Delirium (PAED) score (Fig. 1a) [12] and other complications were assessed on arrival in the PACU and every 10 min until discharge from the PACU. The pain score (Children's Hospital of Eastern Ontario Pain scale; CHEOPS, Fig. 1b [13]) was also assessed on arrival in the PACU, at $30 \mathrm{~min}$ after arrival, and at discharge. When the PAED score was greater than 12, which was considered as the presence of emergence derlirium [14], nalbuphine $0.1 \mathrm{mg} / \mathrm{kg}$ was administered intravenously. When the CHEOPS score was more than 7 , ketorolac $0.5 \mathrm{mg} / \mathrm{kg}$ was administered intravenously if the patients did not receive nalbuphine. Patients were discharged from the PACU when they had a modified Aldrete score greater than 9 . The patients were continuously monitored for complications, including nausea, vomiting and respiratory concerns. Symptoms of hypermagnesaemia, such as hypotension, bradycardia, lethargy, paralysis and headache, were also monitored until

\begin{tabular}{llllll}
\hline A. PAED score & \multicolumn{1}{l}{} \\
\hline Behaviour & Not at all & Just a little & Quite a bit & Very much & Extremely \\
\hline Makes eye contact with caregiver & 4 & 3 & 2 & 1 & 0 \\
Actions are purposeful & 4 & 3 & 2 & 1 & 0 \\
Aware of surroundings & 4 & 3 & 2 & 1 & 0 \\
Restless & 0 & 1 & 2 & 3 & 4 \\
Inconsolable & 0 & 1 & 2 & 3 & 4 \\
\hline
\end{tabular}

B. CHEOP scale

\begin{tabular}{|c|c|c|c|c|c|c|}
\hline Points & Crying & $\begin{array}{l}\text { Facial } \\
\text { expressions }\end{array}$ & Child verbal & Torso & Touch & Legs \\
\hline 0 & Smiling & Smiling & Positive & & & \\
\hline 1 & No cry & Composed & $\begin{array}{l}\text { None, complaints } \\
\text { other than pain }\end{array}$ & Neutral & Not touching & Neutral \\
\hline 2 & $\begin{array}{l}\text { Moaning, } \\
\text { crying }\end{array}$ & Grimace & $\begin{array}{l}\text { Pain-related } \\
\text { complaints, both } \\
\text { pain and nonpain- } \\
\text { related complaint }\end{array}$ & $\begin{array}{l}\text { Shifting, tense, } \\
\text { shivering, upright, } \\
\text { restrained }\end{array}$ & $\begin{array}{l}\text { Reach, touch, grab, } \\
\text { restrained }\end{array}$ & $\begin{array}{l}\text { Squirming kicking, } \\
\text { drawn up, tensed, } \\
\text { standing, } \\
\text { restrained }\end{array}$ \\
\hline 3 & Screaming & & & & & \\
\hline
\end{tabular}

Fig. 1 Pediatric Anaesthesia Emergence Delirium score (a) and Children's Hospital of Eastern Ontario Pain scale (b) 
the patients were discharged from the ambulatory surgery centre.

\section{Statistical analysis}

The primary outcome of this study was the PAED score in both groups. The occurrence of emergence delirium was defined when the PAED scores were $\geq 12$ at any time point in the PACU. The secondary outcomes included the incidence of emergence delirium during PACU stay, CHEOPS score, incidence of nausea, vomiting and respiratory complications, and length of PACU stay.

The sample size was calculated based on a previous study [6] that investigated the effects of intra-operative magnesium sulphate administration on the incidence of emergence delirium in children who had undergone adenotonsillectomy. In that study, the respective rates of emergence delirium in the magnesium and the control group were 36 and $72 \%$, respectively. Thus, the sample size required for our study was calculated to be approximately 30 patients per group, with an alpha error of 0.05 and a power of 0.8 , as determined via PASS software 2008 (version 8.0.16; NCSS statistical software, Kaysville, UT, USA). Based on an attrition rate of up to $10 \%$, a total of 66 patients were enrolled.

All data were analysed using SPSS for Windows (version 23.0; IBM Corp., Armonk, NY, USA). Data normality was assessed using the Kolmogorov-Smirnov test. Categorical variables are expressed as numbers and percentages, and continuous variables as means and standard deviations or medians and interquartile ranges. The Chi-square test was used to assess the significance of categorical data comparisons, and the Fisher's exact test was used when the expected count of $>20 \%$ cells was less than five. The Pearson's correlational analysis was performed to assess the correlation between the preoperative anxiety and PAED scores. The Student's $t$-test or the Mann-Whitney rank-sum test were used to examine the significance of continuous data comparisons. Repeated measures data were analysed by the analysis of variance, and the Bonferroni's correction was used for post-hoc analysis. All $p$ values $<0.05$ were considered statistically significant.

\section{Results}

A total of 66 paediatric patients were initially enrolled from June to December 2017, and randomised into two groups. One patient in the magnesium group was subsequently excluded due to a lack of PAED and pain score assessment. Therefore, data from 65 children (33 and 32 in the control and the magnesium group, respectively) were analysed (Fig. 2).

Table 1 shows the demographic data of patients in the magnesium and the control groups. There were no significant differences in baseline characteristics including the preoperative m-YPAS scores between the two groups.

Table 2 shows the postoperative PAED and the CHEOPS scores in both groups. The median PAED scores over time did not differ significantly $(p=0.806)$ between the two groups. Figure 3 a shows the PAED scores over time in both groups. The incidences of emergence delirium were $26(78.8 \%)$ and $27(84.4 \%)$ in the control and the magnesium groups, respectively (OR $0.69,95 \%$ CI $0.19-2.44, p=0.56$ ).

The CHEOPS scores over time did not differ significantly between the two groups (Fig. 3b). No rescue analgesics were administered in the PACU in either group. The m-YPAS score was not significantly correlated with the PAED score at any time-point (PACU entry, $r=0.1$, $p=0.438$; after $10 \mathrm{~min}, r=0.12, p=0.336$; after $20 \mathrm{~min}$, $r=0.04, p=0.750$; after $30 \mathrm{~min}, r=0.07, p=0.599$; exiting PACU, $r=0.13, p=0.343$ ).

Table 3 shows the intraoperative variable data in both groups. The peak inspiratory pressure, the mean sevoflurane concentration, and mean bispectral index value during surgery did not differ significantly in the two groups. There were no differences in the intraoperative mean heart rate and blood pressures between the two groups. During emergence, the diastolic and mean blood pressures were higher in the control group than in the magnesium group (diastolic blood pressure: 68 [15] vs 60 [11] $\mathrm{mmHg}$, mean differences [95\% CI], 8 [3-13] $\mathrm{mmHg}, p=0.004$; mean blood pressure: 84 [13] vs 76 [10] $\mathrm{mmHg}$, mean differences [95\% CI], 7 [1-13] $\mathrm{mmHg}, p=0.015)$.

In the PACU, no patient experienced nausea and vomiting. There were no significant complications during the PACU stay in both groups. Moreover, the length of stay at the PACU was similar between the two groups.

\section{Discussion}

In this study, we found that magnesium supplementation during strabismus surgery had no significant effect on the incidence of emergence delirium and postoperative pain in children. In addition, there was no significant difference in respiratory complications, length of PACU stay, and other intraoperative parameters between the magnesium and control groups. Lastly, there were no complications associated with intraoperative magnesium supplementation.

Although the mechanism of emergence delirium after general anaesthesia has not been clearly defined, there are some well-known risk factors including young age, no previous surgery, ophthalmology procedures, otorhinolaryngology procedures, volatile anaesthetics such as sevoflurane, and preoperative anxiety [2, 15]. In addition, postoperative pain evidently may have a role in emergence delirium because the administration of 
Table 1 Demographic characteristics of the study population

\begin{tabular}{|c|c|c|c|}
\hline & $\begin{array}{l}\text { Control } \\
(n=33)\end{array}$ & $\begin{array}{l}\text { Magnesium } \\
(n=32)\end{array}$ & $P$ value \\
\hline Age (years) & $4.4 \pm 0.9$ & $4.0 \pm 1.2$ & 0.218 \\
\hline $\operatorname{Sex}(M / F, \%)$ & $14 / 19(42.4 / 57.6)$ & $14 / 18(43.8 / 56.3)$ & 0.914 \\
\hline Height (cm) & $108.6 \pm 8.0$ & $105.4 \pm 9.0$ & 0.135 \\
\hline Weight (kg) & $18.4 \pm 3.0$ & $17.4 \pm 3.1$ & 0.176 \\
\hline Operation time (min) & $25(20-35)$ & $20(15-28.75)$ & 0.138 \\
\hline Anesthesia time (min) & $44.8 \pm 2.6$ & $40.8 \pm 10.9$ & 0.180 \\
\hline Size of laryngeal mask airway $(2 / 2.5, \%)$ & 26/7 (78.8/21.2) & 28/4 (87.5/12.5) & 0.511 \\
\hline \multicolumn{4}{|l|}{ m-YPAS } \\
\hline Activity & $2.0(1.0-2.0)$ & $2.0(1.0-2.0)$ & 0.281 \\
\hline Vocalization & $2.0(1.0-3.0)$ & $2.0(1.0-3.0)$ & 0.781 \\
\hline Emotional expressivity & $2.0(1.25-3.0)$ & $2.0(1.0-3.0)$ & 0.300 \\
\hline State of apparent arousal & $2.0(1.0-2.75)$ & $1.0(1.0-2.0)$ & 0.534 \\
\hline Use of parents & $2.0(1.25-3.0)$ & $2.0(1.0-3.0)$ & 0.501 \\
\hline Total score & $47.5(30.4-58.0)$ & $41.7(28.3-60.0)$ & 0.465 \\
\hline
\end{tabular}

Data are presented as mean \pm standard deviations, median (interquartile ranges) or number (percentage)

$m$-YPAS Modified Yale Preoperative Anxiety Scale

analgesics, including opioids, has been reported to prevent the emergence delirium in children $[16,17]$.

In this report, the term 'emergence delirium' was used to describe the behavioural change following general anaesthesia to maintain consistency with the referenced reports. However, there have been inconsistent use of the terms 'delirium' and 'agitation' in the literature. Emergence delirium refers to an altered state of consciousness, which begins with emergence from anaesthesia and continues through the early recovery period. On the other hand, emergence agitation is an umbrella term, and is affected by emergence delirium, pain, and several

Table 2 Postoperative PAED and CHEOPS scores in both groups

\begin{tabular}{llll}
\hline & $\begin{array}{l}\text { Control } \\
(\boldsymbol{n}=\mathbf{3 3})\end{array}$ & $\begin{array}{l}\text { Magnesium } \\
(\boldsymbol{n}=\mathbf{3 2})\end{array}$ & $\boldsymbol{P}$ value \\
\hline PAED score & & & $0.806^{*}$ \\
PACU in & $15.0(0-18.0)$ & $16.5(0-19.0)$ & 0.417 \\
$10 \mathrm{~min}$ & $12.0(0-15.0)$ & $14.0(0-17.0)$ & 0.313 \\
$20 \mathrm{~min}$ & $10.0(0-14.0)$ & $11.0(0-15.0)$ & 0.253 \\
30 min & $4.5(0-12.25)$ & $8.0(0-15.0)$ & 0.171 \\
PACU out & $7.5(0-12.0)$ & $5(0-15.0)$ & 0.967 \\
CHEOPS score & & & $0.623^{*}$ \\
PACU in & $9.0(4.0-11.0)$ & $10.0(4.0-12.0)$ & 0.390 \\
30 min & $7.0(4.0-8.0)$ & $7.0(4.0-9.75)$ & 0.199 \\
PACU out & $7.0(4.0-8.0)$ & $7.0(4.0-10.0)$ & 0.664
\end{tabular}

Data are presented as median (interquartile ranges)

* $P$ value from repeated measures ANOVA

CHEOPS Children's Hospital of Eastern Ontario Pain scale, PACU

Postanaesthetic are unit, PAED Pediatric anesthesia emergence delirium other factors $[12,18]$. In this study, PAED scores were used to assess 'delirium' apart from pain.

The activation of N-methyl-D-aspartate (NMDA) receptor changes the excitatory properties of neurons that can induce seizures, and as magnesium is an NMDA receptor antagonist it can have sedative and anticonvulsive effects. In addition, magnesium has analgesic effects and can lead to a reduction in perioperative opioid consumption by blocking the NMDA receptors, which are involved in nociception [9]. Therefore, considering the effect of magnesium and the mechanism of emergence delirium, it is reasonable to expect that magnesium may reduce emergence delirium.

There are limited data pertaining to the association between magnesium supplementation and reduced emergence delirium [6, 7]. According to Abdulatif et al. [6], $30 \mathrm{mg} / \mathrm{kg}$ bolus intravenous magnesium sulphate followed by $10 \mathrm{mg} / \mathrm{kg}$ per h during sevoflurane anaesthesia reduced the incidence of emergence delirium with a relative risk of 0.51 in children undergoing adenotonsillectomy [6]. Bondok et al. [7] reported that no emergence delirium occurred in male children who received magnesium supplementation undergoing elective inguinal herniorrhaphy.

To the best of our knowledge, this is the first study that evaluated the effect of magnesium supplementation in children undergoing ophthalmic surgery. There were some differences between the present study and previous studies. In two studies demonstrating the beneficial effect of magnesium, combination analgesic therapy was used with opioids, non-steroidal anti-inflammatory drugs, and regional block $[6,7]$. In our study, we used 


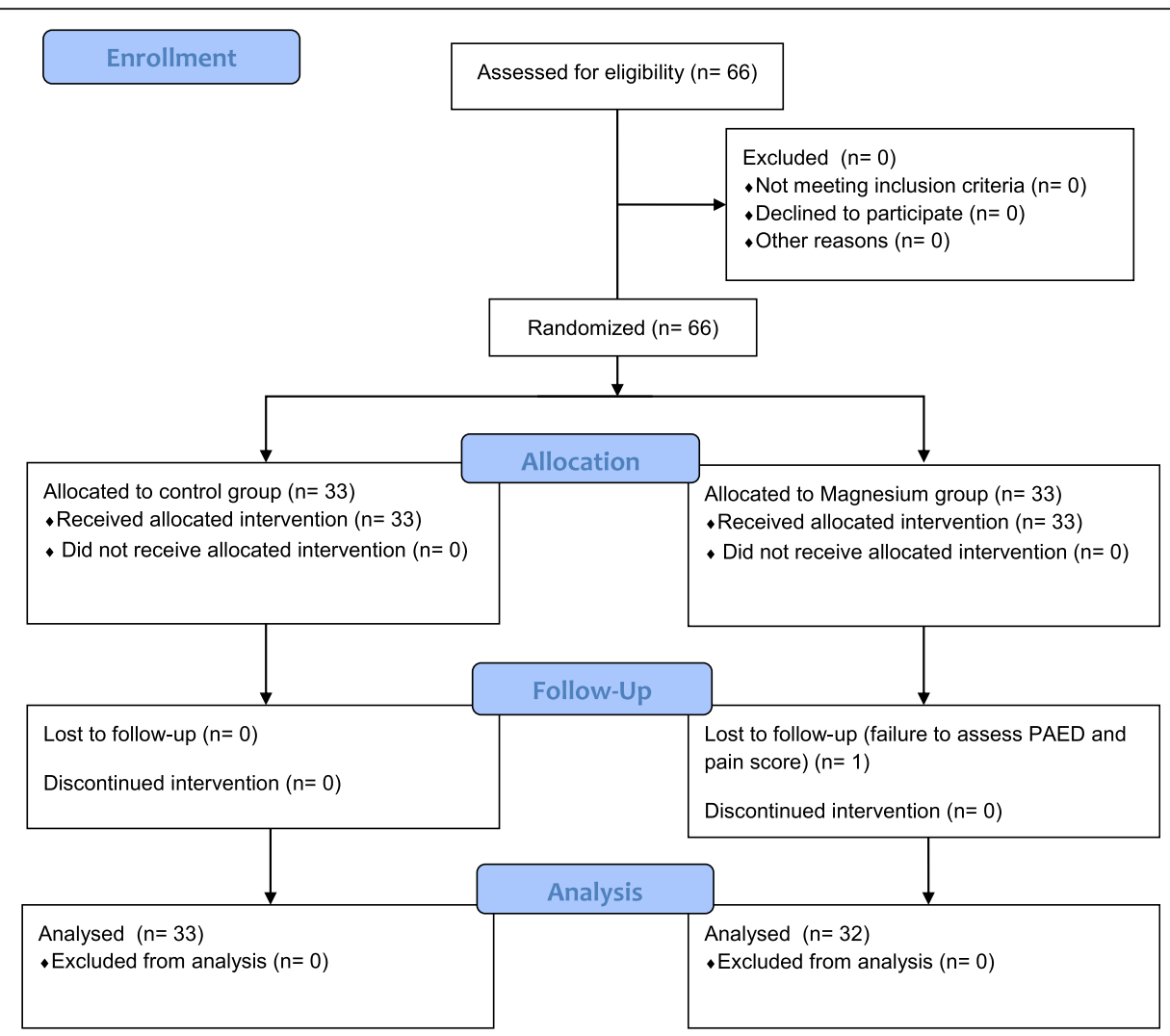

Fig. 2 CONSORT diagram

propacetamol only for pain control to minimise the confounding effects of analgesics. The differences in the analgesic use and type of surgery might contribute to the higher incidence of emergence delirium in this study (approximately $80 \%$ ) compared to that in previous studies (35\% [6] and 50\% [7]).

There are several possible reasons for the nonsignificant association between magnesium and emergence delirium observed in this study. Magnesium concentrations may have been within the normal range even in the control group, as it was reported by Apan et al. [8] Therefore, the additional increase in magnesium concentration may not have functioned to reduce emergence delirium or pain. In addition, genetic factors may also be relevant. Genetic differences in pain sensitivity [19], responses to analgesics due to alterations of pharmacokinetic and pharmacodynamic parameters [20, 21], and emergence delirium [22] have been reported. Additionally, there may be differences associated with race. Finally, there might be other factors that influenced the occurrence of emergence delirium. According to Joo et al., emergence delirium was associated with the level of invasiveness of the procedure in children undergoing ophthalmic surgery [23]. There were wide variations in operating time in this study, and we speculated that complexity of surgery, surgical skill, or operation time might be potential factors affecting the recovery characteristics.

Preoperative anxiety can affect emergence delirium [2, 24], and several studies have reported their association $[25,26]$. However, in this study, we could not find a correlation between the m-YPAS and PAED scale. Our result was similar to that of a previous study, suggesting that visual disturbances might play a greater role in emergence delirium compared with preoperative anxiety [23].

Previous studies concluded that perioperative adjuvant magnesium sulphate administration reduced the requirements for nondepolarizing neuromuscular blockers [27-29]. We also expected that intraoperative magnesium supplementation could reduce the peak inspiratory pressure and spontaneous respiratory effort, as magnesium has property for potentiation of muscle relaxation and, thus, no neuromuscular blockade was used in the present study [10]. However, we could not find the group difference in the peak inspiratory pressure and incidence of spontaneous respiratory effort.

On the other hand, the control group showed higher diastolic and mean blood pressure during the emergence period when compared to the magnesium group. Magnesium has vasodilatory effects, and is known to reduce the need for alpha-beta blockers [9]. Hypotension is one of the complications of magnesium administration, 

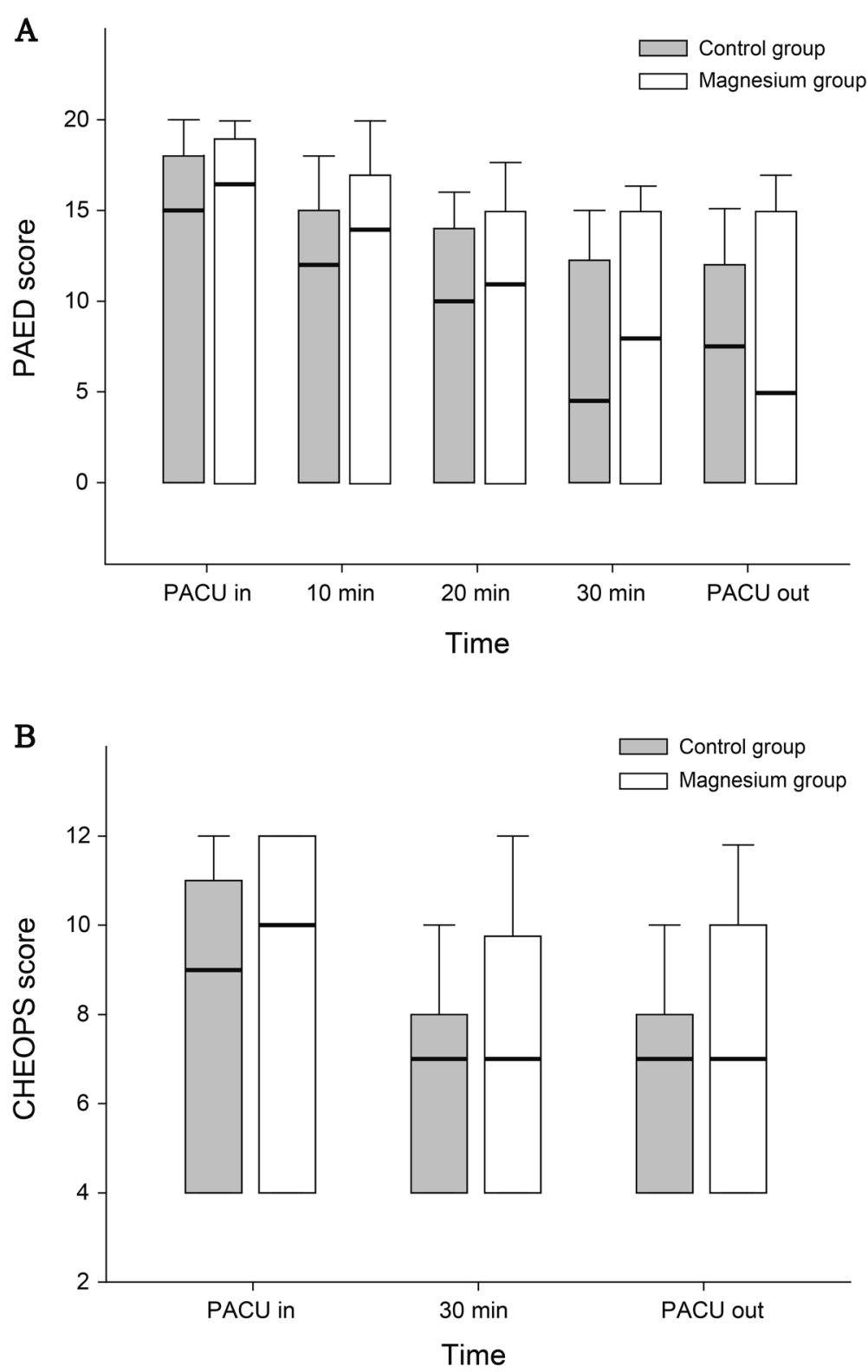

Fig. 3 The PAED score (a) and the CHEOPS score (b) over time in both groups. The boundary of the box indicates the 25th and 75th percentile, and a bold line within the box marks the median. The error bars indicate the 10th and 90th percentiles. PAED, Pediatric Anaesthesia Emergence Delirium; CHEOPS, Children's Hospital of Eastern Ontario Pain Scale

which can occur when the serum magnesium level exceeds $3-4 \mathrm{mg} / \mathrm{dl}[9]$. Although we could not assess the serum magnesium level, there were no patients with significant hypotension. Sympathetic tone usually increases during the emergence period, and we speculated that magnesium may prevent the further increase in blood pressure in the magnesium group.

Our study had some limitations. The sample size was too small with regard to the statistical power, as it was calculated based on previous studies, in which there were significant differences between the control and magnesium groups [6]. Additionally, the serum magnesium levels were not evaluated before and after the administration of magnesium sulphate in all patients. Magnesium supplementation can be helpful when hypomagnesemia is obvious, but hypomagnesemia may not be commonly associated with short operations and minimal fasting times [8]. Second, there might be a possibility of hypermagnesemia and safety issue should be considered. The possible adverse effects of hypermagnesemia are bradycardia and hypotension. However, there were no cases of clinical consequences and no need for 
Table 3 Intraoperative and postoperative variables of both groups

\begin{tabular}{|c|c|c|c|}
\hline & $\begin{array}{l}\text { Control } \\
(n=33)\end{array}$ & $\begin{array}{l}\text { Magnesium } \\
(n=32)\end{array}$ & $P$ value \\
\hline Number of attempts for laryngeal mask airway insertion & $1(1-1)$ & $1(1-1)$ & 0.965 \\
\hline Number of cases for laryngeal mask repositioning & 0 & 0 & . \\
\hline Mean sevoflurane concentration (vol\%) & $2.7 \pm 0.3$ & $2.5 \pm 0.4$ & 0.707 \\
\hline Intraoperative mean BIS value & $50 \pm 4$ & $49 \pm 3$ & 0.192 \\
\hline \multicolumn{4}{|l|}{ Peak inspiratory pressure $\left(\mathrm{cmH}_{2} \mathrm{O}\right)$} \\
\hline Maximum pressure & $15.2 \pm 4.6$ & $15.6 \pm 4.8$ & 0.790 \\
\hline Minimum pressure & $12.7 \pm 2.2$ & $13.3 \pm 2.4$ & 0.359 \\
\hline \multicolumn{4}{|l|}{ Intraoperative hemodynamic parameters } \\
\hline Heart rate (bpm) & $129 \pm 18$ & $134 \pm 13$ & 0.219 \\
\hline Systolic blood pressure (mmHg) & $92 \pm 7$ & $93 \pm 10$ & 0.611 \\
\hline Diastolic blood pressure (mmHg) & $49 \pm 8$ & $48 \pm 8$ & 0.391 \\
\hline Mean blood pressure $(\mathrm{mmHg})$ & $66 \pm 9$ & $63 \pm 7$ & 0.231 \\
\hline \multicolumn{4}{|l|}{ Hemodynamic parameters during emergence } \\
\hline Heart rate (bpm) & $122 \pm 19$ & $124 \pm 14$ & 0.628 \\
\hline Systolic blood pressure (mmHg) & $107 \pm 15$ & $101 \pm 11$ & 0.087 \\
\hline Diastolic blood pressure (mmHg) & $68 \pm 15$ & $60 \pm 11$ & $0.004^{*}$ \\
\hline Mean blood pressure (mmHg) & $84 \pm 13$ & $76 \pm 10$ & $0.015^{*}$ \\
\hline Time from surgery end to PACU admission (min) & $5.9 \pm 2.2$ & $6.1 \pm 2.8$ & 0.733 \\
\hline Respiratory event during emergence & $8(24.2 \%)$ & $8(25.0 \%)$ & 1.0 \\
\hline Laryngospasm & 0 & $1(3.1 \%)$ & 1.0 \\
\hline Desaturation & $4(12.1 \%)$ & $2(6.3 \%)$ & 0.672 \\
\hline Breath holding & $2(6.1 \%)$ & 0 & 0.492 \\
\hline Coughing & $4(12.1 \%)$ & $5(15.6 \%)$ & 1.0 \\
\hline Length of PACU stay & $34.2(3.1)$ & $34.5(5.4)$ & 0.771 \\
\hline
\end{tabular}

Data are presented as median (interquartile ranges), mean \pm standard deviations or number (percentages)

${ }^{*} P<0.05$ between the control and magnesium groups

$B I S$ Bispectral index, PACU Postanaesthetic care unit

treatment withdrawal in paediatric population [9]. In addition, there were no critical incidents related to magnesium supplementation in the present study. Third, the incidence of emergence delirium was higher than expected when calculating the sample size. This may be associated with the relatively high pain scores in our patients. When preschool children with emergence delirium have pain, pain-related behaviour could be assessed as emergence delirium [30]. Additionally, postoperative nausea and vomiting may present as agitation. Finally, the PAED and pain scores were assessed only in the PACU. The data would have been more informative and valuable if the patients were followed up for emergence delirium and pain in the first $24 \mathrm{~h}$ postoperatively.

In conclusion, in our study magnesium supplementation had no significant effect on emergence agitation or postoperative pain in children who had undergone strabismus surgery. Other strategies to minimise emergence agitation in children should also be investigated.

\section{Abbreviations}

BIS: Bispectral index; CHEOPS: Children's Hospital of Eastern Ontario Pain scale; m-YPAS: Modified Yale Preoperative Anxiety Scale; NMDA: N-methyl-Daspartate; PACU: Postanaesthetic care unit; PAED: Paediatric Anaesthesia Emergence Delirium

\section{Acknowledgments}

None.

Authors' contributions

KHS, LJH and KJT designed the study, performed the statistical analysis, and drafted the manuscript. CSE, LMK and JYE interpreted the data, revised the manuscript, collected the data and assisted in drafting the manuscript. KEH revised the manuscript and approved the version to be published. All authors read and approved the final submitted version of the manuscript.

\section{Funding}

This study was supported by grant 800-20140532 from Seoul National University College of Medicine, Seoul, Korea.

Availability of data and materials

The datasets used and/or analyzed during the current study are available from the corresponding author on reasonable request. 


\section{Ethics approval and consent to participate}

The study protocol was approved by the Institutional Review Board of the Seoul National University Hospital (approval number: H1703-110-840; date of approval: May 8, 2017) and was registered at https://clinicaltrials.gov (number: NCT03132701; principal investigator: Hee-Soo Kim; date of registration: April 9, 2017). The anaesthesiologists involved in the study obtained written informed consent from the parents or their guardians after explaining the study protocol to them.

\section{Consent for publication}

Not applicable.

\section{Competing interests}

The authors declare that they have no competing interests.

Received: 20 August 2020 Accepted: 20 October 2020

Published online: 18 November 2020

\section{References}

1. Cole JW, Murray DJ, McAllister JD, Hirshberg GE. Emergence behaviour in children: defining the incidence of excitement and agitation following anaesthesia. Paediatr Anaesth. 2002;12(5):442-7.

2. Mason KP. Paediatric emergence delirium: a comprehensive review and interpretation of the literature. BJA. 2017;118(3):335-43.

3. de Baaij JH, Hoenderop JG, Bindels RJ. Magnesium in man: implications for health and disease. Physiol Rev. 2015;95(1):1-46.

4. Lysakowski C, Dumont L, Czarnetzki C, Tramer MR. Magnesium as an adjuvant to postoperative analgesia: a systematic review of randomized trials. Anesth Analg. 2007;104(6):1532-9.

5. Albrecht E, Kirkham KR, Liu SS, Brull R. Peri-operative intravenous administration of magnesium sulphate and postoperative pain: a metaanalysis. Anaesthesia. 2013;68(1):79-90.

6. Abdulatif M, Ahmed A, Mukhtar A, Badawy S. The effect of magnesium sulphate infusion on the incidence and severity of emergence agitation in children undergoing adenotonsillectomy using sevoflurane anaesthesia. Anaesthesia. 2013;68(10):1045-52.

7. Bondok R, Ali R. Magnesium sulfate reduces sevoflurane-induced emergence agitation in pediatric patients. Ain Shams J Anaesthesiol. 2014; 7(3):282-8.

8. Apan A, Aykac E, Kazkayasi M, Doganci N, Tahran FD. Magnesium sulphate infusion is not effective on discomfort or emergence phenomenon in paediatric adenoidectomy/tonsillectomy. Int J Pediatr Otorhinolaryngol. 2010;74(12):1367-71.

9. Eizaga Rebollar R, Garcia Palacios MV, Morales Guerrero J, Torres LM. Magnesium sulfate in pediatric anesthesia: the super adjuvant. Paediatr Anaesth. 2017;27(5):480-9.

10. Do S-H. Magnesium: a versatile drug for anesthesiologists. Korean J Anesthesiol. 2013;65(1):4-8.

11. Kain ZN, Mayes LC, Cicchetti DV, Bagnall AL, Finley JD, Hofstadter MB. The Yale preoperative anxiety scale: how does it compare with a "gold standard"? Anesth Analg. 1997;85(4):783-8.

12. Sikich $\mathrm{N}$, Lerman J. Development and psychometric evaluation of the pediatric anesthesia emergence delirium scale. Anesthesiology. 2004;100(5): 1138-45.

13. McGrath PA. The multidimensional assessment and management of recurrent pain syndromes in children. Behav Res Ther. 1987;25(4):251-62.

14. Driscoll JN, Bender BM, Archilla CA, Klim CM, Hossain MJ, Mychaskiw GN, Wei JL. Comparing incidence of emergence delirium between sevoflurane and desflurane in children following routine otolaryngology procedures. Minerva Anestesiol. 2017:83(4):383-91.

15. Voepel-Lewis T, Malviya S, Tait AR. A prospective cohort study of emergence agitation in the pediatric postanesthesia care unit. Anesth Analg. 2003;96(6):1625-30.

16. Fan KT, Lee TH, Yu KL, Tang CS, Lu DV, Chen PY, Soo LY. Influences of tramadol on emergence characteristics from sevoflurane anesthesia in pediatric ambulatory surgery. Kaohsiung J Med Sci. 2000;16(5):255-60.

17. Dahmani S, Stany I, Brasher C, Lejeune C, Bruneau B, Wood C, Nivoche Y, Constant I, Murat I. Pharmacological prevention of sevoflurane- and desflurane-related emergence agitation in children: a meta-analysis of published studies. Br J Anaesth. 2010;104(2):216-23.
18. Bajwa SA, Costi D, Cyna AM. A comparison of emergence delirium scales following general anesthesia in children. Paediatr Anaesth. 2010;20(8):704-11.

19. Crews KR, Gaedigk A, Dunnenberger HM, Leeder JS, Klein TE, Caudle KE, Haidar CE, Shen DD, Callaghan JT, Sadhasivam S, et al. Clinical Pharmacogenetics implementation consortium guidelines for cytochrome P450 2D6 genotype and codeine therapy: 2014 update. Clin Pharmacol Ther. 2014;95(4):376-82.

20. Manworren RC, Jeffries L, Pantaleao A, Seip R, Zempsky WT, Ruano G. Pharmacogenetic testing for analgesic adverse effects: pediatric case series. Clin J Pain. 2016;32(2):109-15.

21. Kolesnikov Y, Gabovits B, Levin A, Voiko E, Veske A. Combined catechol-Omethyltransferase and mu-opioid receptor gene polymorphisms affect morphine postoperative analgesia and central side effects. Anesth Analg. 2011;112(2):448-53.

22. Kim JH. Mechanism of emergence agitation induced by sevoflurane anesthesia. Korean J Anesthesiol. 2011;60(2):73-4.

23. Joo J, Lee $\mathrm{S}$, Lee $\mathrm{Y}$. Emergence delirium is related to the invasiveness of strabismus surgery in preschool-age children. J Int Med Res. 2014;42(6): $1311-22$.

24. Kain ZN, Caldwell-Andrews AA, Maranets I, McClain B, Gaal D, Mayes LC, Feng $\mathrm{R}$, Zhang $\mathrm{H}$. Preoperative anxiety and emergence delirium and postoperative maladaptive behaviors. Anesth Analg. 2004;99(6):1648-54

25. Weldon BC, Bell M, Craddock T. The effect of caudal analgesia on emergence agitation in children after sevoflurane versus halothane anesthesia. Anesth Analg. 2004;98(2):321-6.

26. Konig MW, Varughese AM, Brennen KA, Barclay S, Shackleford TM, Samuels PJ, Gorman K, Ellis J, Wang Y, Nick TG. Quality of recovery from two types of general anesthesia for ambulatory dental surgery in children: a doubleblind, randomized trial. Paediatr Anaesth. 2009;19(8):748-55.

27. Na HS, Lee JH, Hwang JY, Ryu JH, Han SH, Jeon YT, Do SH. Effects of magnesium sulphate on intraoperative neuromuscular blocking agent requirements and postoperative analgesia in children with cerebral palsy. Br J Anaesth. 2010;104(3):344-50.

28. Lee DH, Kwon IC. Magnesium sulphate has beneficial effects as an adjuvant during general anaesthesia for caesarean section. Br J Anaesth. 2009;103(6): 861-6.

29. Ryu JH, Kang MH, Park KS, Do SH. Effects of magnesium sulphate on intraoperative anaesthetic requirements and postoperative analgesia in gynaecology patients receiving total intravenous anaesthesia. Br J Anaesth. 2008;100(3):397-403

30. Aroke EN, Crawford SL, Dungan JR. Pharmacogenetics of ketamine-induced emergence phenomena: a pilot study. Nurs Res. 2017;66(2):105-14.

\section{Publisher's Note}

Springer Nature remains neutral with regard to jurisdictional claims in published maps and institutional affiliations.

Ready to submit your research? Choose BMC and benefit from:

- fast, convenient online submission

- thorough peer review by experienced researchers in your field

- rapid publication on acceptance

- support for research data, including large and complex data types

- gold Open Access which fosters wider collaboration and increased citations

- maximum visibility for your research: over $100 \mathrm{M}$ website views per year

At BMC, research is always in progress.

Learn more biomedcentral.com/submissions 